Brit. Heart J., 1965, 27, 618.

\title{
ANTICOAGULANTS AND MITRAL VALVOTOMY
}

\author{
BY \\ BLANCA SMITH, A. UMAPATHY, H. H. BENTALL, AND W. P. CLELAND \\ From the Cardiothoracic Unit, Department of Surgery, Postgraduate Medical School, Hammersmith \\ Hospital, London \\ Received November 23, 1964
}

Prophylactic anticoagulant treatment prior to mitral valvotomy was first recommended by Storm and Hansen (1955). Several authors have since confirmed that this measure significantly reduces the incidence of operative and post-operative embolism. But this dreaded complication was entirely abolished only in Storm and Hansen's series and in the first series reported by Miscall et al. (1962). In all other series (Table I) a few patients had an embolic episode despite the use of anticoagulants. This failure has resulted in reluctance to introduce anticoagulant prophylaxis. The question arises as to whether anticoagulants inevitably fail to prevent embolism in some patients (McDevitt et al., 1958) or whether failures are due to errors in management and are thus preventable. The detailed management of those patients in whom prophylaxis failed is not reported except in the series of Uglov and Potashov (1962) and Miscall et al. (1962), when insufficient reduction of the prothrombin time is mentioned.

The criteria for satisfactory prophylactic anticoagulant treatment are difficult to define since the requirements of an adequate pre-operative régime have not yet been agreed. The management of anticoagulants has been evolved from the personal experience of each author, and their recommendations differ widely. The minimum period of pre-operative anticoagulation, the level of the prothrombin time, and the need for stopping anticoagulants before operation, are among the controversial issues. A period of pre-operative anticoagulation of three weeks was used by Miscall et al. (1962); four weeks or more were recommended by Beaumont, Moeri, and Lenègre (1957), Ricordeau and Balansa (1957), and Dahlgren and Björk (1962); whereas Storm and Hansen (1955)

TABLE I

Comparative Incidence of Embolism Following Mitral Valvotomy: A Review of Latest Reports

\begin{tabular}{|c|c|c|c|c|}
\hline \multirow{2}{*}{ Author } & \multicolumn{2}{|c|}{ No anticoagulants } & \multicolumn{2}{|c|}{ On anticoagulants } \\
\hline & No. of patients & No. with emboli & No. of patients & No. with emboli \\
\hline $\begin{array}{l}\text { *Storm and Hansen (1955) } \\
\text { Ricordeau and Balansa (1957) } \\
\text { Beaumont et al. (1957) } \\
\text { Miscall et al. }(1962)\end{array}$ & $\begin{array}{r}26 \\
36 \\
258\end{array}$ & $\begin{array}{l}8(30 \cdot 8) \\
9(25 \cdot 0) \\
4(1 \cdot 6)\end{array}$ & $\begin{array}{l}26^{*} \\
35 \\
113\end{array}$ & $\begin{array}{l}0 \\
4(11 \cdot 4) \\
2(1 \cdot 7)\end{array}$ \\
\hline $\begin{array}{cccc}* \text { I series } & \ldots & \ldots & \ldots \\
\text { II series } & \ldots & & \\
\text { Uglov and Potashov (1962) } & \ldots\end{array}$ & $\begin{array}{l}35 \\
40 \\
78\end{array}$ & $\begin{array}{r}9(25 \cdot 7) \\
11(27 \cdot 5) \\
8(10 \cdot 3)\end{array}$ & $\begin{array}{l}35^{*} \\
48 \\
76\end{array}$ & $\begin{array}{l}0 \\
2(4 \cdot 2) \\
1(1 \cdot 3)\end{array}$ \\
\hline
\end{tabular}

* "Continuous therapy." All other series "interrupted therapy." Percentages are given in parentheses. 
regarded one week as sufficient. Carter et al. (1958) and Glenn and Holswade (1960) both advocated a minimum of six weeks if the patient had had a recent embolus.

The recommended prothrombin time varies widely between 20 and 60 per cent in different series. As concern about operating under anticoagulants is prevalent, the majority of authors recommend changes in the pre-operative anticoagulation régime as the day of operation draws near. Glenn and Holswade (1960) stopped anticoagulants a variable number of days before operation, while Uglov and Potashov (1962) decreased the dose gradually.

Because of the risk of embolism following abrupt cessation of anticoagulants, Dahlgren and Björk (1962) and Uglov and Potashov (1962) changed the anticoagulant to heparin 48 hours before operation, as did Dubost, Blondeau, and Piwnica (1962). Miscall et al. (1962), in his second series, used the "interrupted therapy" method, stopping anticoagulants 36 to 48 hours before operation and giving vitamin $\mathrm{K}$ to bring the prothrombin time to normal on the day of operation. Only Storm and Hansen (1955) and Miscall et al. (second series, 1962) maintained their patients on an unaltered régime through the day of operation and into the post-operative period.

The type of anticoagulant used also varied from author to author. Warfarin sodium (coumadin sodium) was used by Glenn and Holswade (1960); dicoumarol by Dahlgren and Björk (1962), and phenindione by Uglov and Potashov (1962). In Ricordeau and Balansa's (1957) series, both drugs, dicoumarol and phenindione, were used.

\section{SubJeCtS AND MeTHOdS}

This paper presents the experience at the Postgraduate Medical School, Hammersmith Hospital. The anticoagulant régime and the indication for its use have passed through several changes since its adoption in 1957. The initial results have been reported by Goodwin (1960). This further study was undertaken in an attempt to establish the safest and most reliable anticoagulant régime. In every patient the scheme of anticoagulation used was compared with the results obtained, both in the prevention of thromboembolic episodes and in the occurrence of bleeding complications. The incidence of embolism and bleeding complications in a comparable group of patients not given anticoagulants has been reviewed. In addition, the occurrence of thrombophlebitis in the treated and untreated groups has been compared.

There were 375 closed mitral valvotomies performed at Hammersmith Hospital between 1951 and 1962 by W.P.C., H.H.B., and Mr. L. L. Bromley. Of these, 114 were given anticoagulants before operation, while 261 were not. The control series was in the main retrospective.

Digital splitting of the valve commissures was used in the great majority of earlier cases. In recent years dilatation has been instrumental, the transatrial route being used initially. At the present time the transventricular route is preferred, and a Tubbs dilator is used almost exclusively.

When anticoagulants were first used, only patients who had had a recent embolism were treated. Now anticoagulants are given routinely, as part of the pre-operative management, to all patients awaiting valvotomy who have had a thromboembolic episode, atrial fibrillation, or pulmonary hypertension.

There has been a gradual tendency to prolong the period of pre-operative anticoagulation. Considering the series as a whole, most patients had their mitral valvotomy two to four weeks after the onset of therapy. The level of prothrombin time sought in earlier cases was about 20 seconds with a control value of 12 seconds, but 25 to 30 seconds is now preferred (prothrombin \% of 40-50). The level of the prothrombin time is determined daily or on alternate days and the dosage of phenindione (which was used exclusively in this study) is changed accordingly.

Before 1960, anticoagulants were stopped several days before operation. Since 1960, anticoagulants have been maintained throughout the operative and post-operative periods. Phenindione is given orally twice daily but the morning dose is omitted on the day of operation. Dosage is resumed on the evening after operation unless post-operative blood loss is excessive. In most instances the dosage is gradually reduced towards the end of the third post-operative week and then discontinued. Occasionally anticoagulants are continued for considerably longer periods, especially if the pulmonary vascular resistance is high, or where cardioversion is being contemplated at a later date.

\section{RESULTS}

Operative and Post-operative Embolism. The 114 patients who had been given anticoagulants will be considered in two groups: 96 patients in whom therapy was continued through the operative 
into the post-operative period, and 18 patients in whom therapy was discontinued some days before the operation.

The former group of 96 patients was analysed according to the length of the pre-operative therapy and the prothrombin levels just before operation. These patients can be further subdivided into a group of 41 who received "adequate" anticoagulation of more than two weeks with prothrombin times of 20-30 seconds and another group of 55 who had received therapy "inadequate" in duration or amount. No embolic episode (however mild) was recorded amongst the 41 patients where the prothrombin times were more than 20 seconds and where therapy had been continued for more than two weeks. Amongst the 55 patients in the inadequate group, four had embolic episodes and these are identified in Table II by their initials. Some of these incidents were mild, but all have been included. It will be noticed that in 2 of these patients the prothrombin times were less than 20 seconds and in the other two therapy had been employed for less than two weeks.

TABLE II

96 Patients on Continuous Anticoagulant Treatment Grouped According to Length of Therapy and LeVel of THE PROTHROMBIN Time at TIMe Of Operation

\begin{tabular}{|c|c|c|c|c|}
\hline \multirow{2}{*}{$\begin{array}{l}\text { Length of pre-operative } \\
\text { anticoagulation (wk.) }\end{array}$} & \multicolumn{3}{|c|}{ Prothrombin time (sec.) } & \multirow{2}{*}{ Total } \\
\hline & $<20$ & $20-29$ & 30 and over & \\
\hline $\begin{array}{l}>6 \\
-6 \\
-4 \\
-3 \\
-2 \\
-1\end{array}$ & $\begin{array}{cr} & 3 \\
& 1 \\
(\text { CO'K) } & 9 \\
\text { (A.M.) } & 8 \\
15 \\
0\end{array}$ & $\begin{array}{r}7 \\
6 \\
15 \\
8 \\
\text { (R.N.) } 12 \\
2\end{array}$ & $\begin{array}{r}0 \\
0 \\
2 \\
2 \\
3 \\
3 \\
\text { (S.B.) } 2\end{array}$ & $\begin{array}{r}10 \\
7 \\
26 \\
19 \\
30 \\
4\end{array}$ \\
\hline Total patients & 36 & 50 & 10 & 96 \\
\hline
\end{tabular}

The initials identify the four patients who had a post-operative embolic episode.

Comparing the incidence of embolism in these two groups of patients, it seems that a scheme of continuous pre-operative anticoagulants for longer than two weeks with prothrombin levels of over 20 seconds gives adequate protection against embolism. When the anticoagulants were inadequate in amount or duration, the incidence of embolism was similar $(7 \cdot 2 \%)$ to that among the 261 patients not given anticoagulants $(9.5 \%)$ (Table III). The embolic process, however, was less severe in the 4 patients who suffered an embolism while on anticoagulants than in the patients in the "interrupted therapy" group who had emboli (Table III).

Of the 18 patients in whom anticoagulants had been discontinued suddenly several days before operation, $5(27.7 \%$ ) had an embolism and 2 had severe thrombophlebitis, a higher percentage than in the untreated group (Table III). This coincides with the experience of Dahlgren and Björk (1962) who reported 5 patients in whom long-term anticoagulants were interrupted several days before operation; 4 of them had emboli and 2 died. These authors felt that "a sudden cessation of anti-thrombotic treatment, once it had been instituted, was more dangerous than if it was continued during the operative and post-operative period."

A review of earlier reports shows that complete protection against thrombo-embolic complications has been achieved only in the two series reporting continuous anticoagulation throughout the operative and post-operative periods (Miscall et al., 1962; Storm and Hansen, 1955).

Furthermore, Miscall et al. reported two series, one with continuous therapy and another with interrupted therapy: there were no emboli in the continuous therapy group, while two emboli occurred in the series treated by the interrupted method which involved stopping anticoagulants 48 hours before operation and giving vitamin $\mathrm{K}$. 
TABLE III

INCIDENCE OF EMBOLISM AMONG 375 Mitral VALVotomies

\begin{tabular}{|c|c|c|c|c|c|c|c|c|}
\hline \multirow{3}{*}{$\begin{array}{l}\text { No. of } \\
\text { patients }\end{array}$} & \multirow{3}{*}{ Therapy } & \multicolumn{3}{|c|}{ Systemic embolism } & \multicolumn{3}{|c|}{ Pulmonary embolism } & \multirow{3}{*}{$\begin{array}{c}\text { Total incidence } \\
\text { No. }\end{array}$} \\
\hline & & \multirow{2}{*}{ No. } & \multicolumn{2}{|c|}{ Outcome } & \multirow{2}{*}{ No. } & \multicolumn{2}{|c|}{ Outcome } & \\
\hline & & & Recovered & Died & & Recovered & Died & \\
\hline \multirow[t]{4}{*}{$\begin{array}{r}261 \\
18\end{array}$} & \multirow{4}{*}{$\begin{array}{l}\text { Not anticoagulated } \\
\text { Anticoagulated "interrupted" } \\
\text { therapy } \\
\text { "Continuous" therapy } \\
\text { A. Anticoagulation inade- } \\
\text { quate ( } 55 \text { patients) } \\
\text { B. Anticoagulation ade- } \\
\text { quate (41 patients) }\end{array}$} & 13 & 5 & 8 & 12 & 11 & 1 & $25(9 \cdot 5)^{*}$ \\
\hline & & 3 & 3 & - & 2 & 2 & - & $5(27 \cdot 7)$ \\
\hline & & 3 & 3 & - & 1 & - & 1 & $4(7.2)$ \\
\hline & & & & - & - & - & - & \\
\hline Total & & 19 & 11 & 8 & 15 & 13 & 2 & $34(9.0)$ \\
\hline
\end{tabular}

* Percentages are given in parenthesis

TABLE IV

InCidence of Post-Operative Thrombophlebitis after Mitral Valvotomy

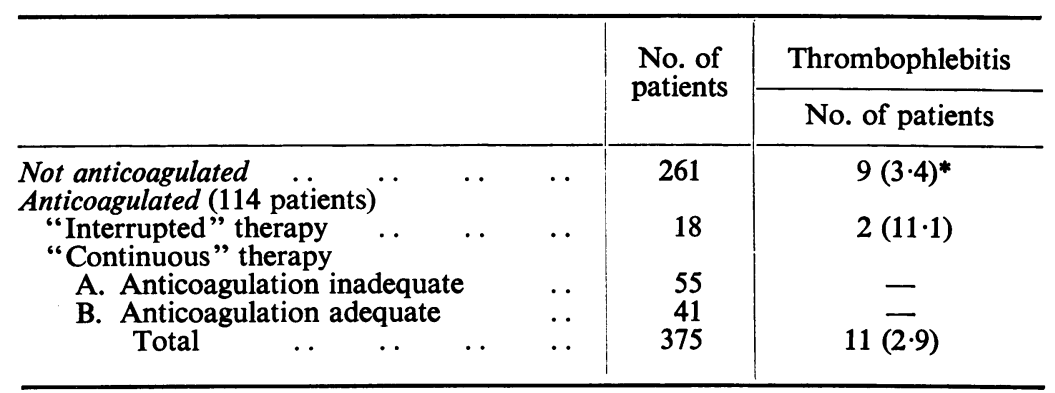

* Percentages are given in parenthesis

Table IV shows that the incidence of thrombophlebitis is also reduced by anticoagulants, there being no episodes of peripheral thrombophlebitis in 96 patients on continuous anticoagulant therapy. The incidence was 3.4 per cent in the untreated group and 11 per cent in the "interrupted" group, harmonizing with the higher incidence of systemic emboli in this group. But even "inadequate" anticoagulation appeared to reduce the risks of serious thrombosis and embolism.

Hamorrhagic Complications. A properly conducted anticoagulant régime must give the patient adequate protection against embolism without hæmorrhagic complications.

The individual blood loss record of the $\mathbf{3 7 5}$ patients in this series was reviewed (Table V) to see how much blood loss accompanied operation, both in patients taking anticoagulants and in the control group. All losses, operative and post-operative, were taken into account. The operative losses included the blood aspirated from the surgical field and the estimated loss in the swabs and sponges weighed first dry and again immediately after use. To these operative losses was added the total post-operative chest drainage. Any additional blood aspirated from the chest was added to the total and the chest aspiration was noted as a complication.

All patients were divided into the following groups, according to the total amount of blood loss. Group A: less than $1000 \mathrm{ml}$; Group B: between $1000 \mathrm{ml}$. and $2000 \mathrm{ml}$.; and Group C: over $2000 \mathrm{ml}$. 
TABLE V

Amount of Blood loss in 375 Patients after Mitral Valvotomies in Relation to ANTICOAGULANTS AND DURATION OF THERAPY

\begin{tabular}{|c|c|c|c|c|}
\hline $\begin{array}{l}\text { No. of } \\
\text { patients }\end{array}$ & & $\begin{array}{l}\text { Group A } \\
<1000 \mathrm{ml} \text {. }\end{array}$ & $\begin{array}{c}\text { Group B } \\
1000-2000 \mathrm{ml} .\end{array}$ & $\begin{array}{c}\text { Group C } \\
>2000 \mathrm{ml} \text {. }\end{array}$ \\
\hline $\begin{array}{l}261 \\
114\end{array}$ & 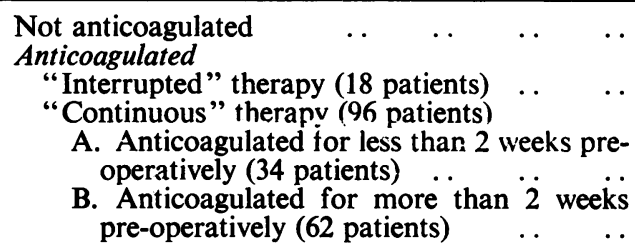 & $\begin{array}{r}228 \\
15 \\
25 \\
55\end{array}$ & $\begin{array}{r}19 \\
3 \\
7 \\
5\end{array}$ & $\begin{array}{r}14 \\
- \\
2 \\
2\end{array}$ \\
\hline Total 375 & & & & \\
\hline
\end{tabular}

TABLE VI

Comparison of Blood Loss at Operation on Patients not Receiving and Receiving ANTICOAGULANT TREATMENT

\begin{tabular}{|c|c|c|c|c|c|c|}
\hline \multirow{3}{*}{ Case No. } & \multirow{2}{*}{\multicolumn{2}{|c|}{$\frac{\text { No anticoagulants }}{\text { First valvotomy }}$}} & \multicolumn{4}{|c|}{ On anticoagulants } \\
\hline & & & \multicolumn{4}{|c|}{ Second valvotomy } \\
\hline & Technique & $\begin{array}{l}\text { Blood loss } \\
\text { (ml.) }\end{array}$ & $\begin{array}{l}\text { Prothrombin } \\
\text { time (sec.) }\end{array}$ & Tecl & & Blood loss (ml.) \\
\hline $\begin{array}{l}1 \\
2 \\
3 \\
4 \\
5 \\
6 \\
7 \\
8 \\
9\end{array}$ & $\begin{array}{c}\text { Digital } \\
", \\
", \\
", \\
\text { Digital and knife } \\
\text { " " " }\end{array}$ & $\begin{array}{l}<1000 \\
" \\
" \\
" \\
" \\
"\end{array}$ & $\begin{array}{l}12 \\
20 \\
20 \\
21 \\
18 \\
21 \\
21 \\
20 \\
17\end{array}$ & $\begin{array}{r}\text { Transventr } \\
\text { ", } \\
\text { ". } \\
\text { ”, } \\
\text { ", }\end{array}$ & $\begin{array}{l}\text { ilator } \\
", \\
" \\
" \\
" \\
"\end{array}$ & $\begin{array}{c}1500 \\
<1000 \\
", \\
" . \\
\dddot{"} \\
2000 \text { and hæmothorax }\end{array}$ \\
\hline
\end{tabular}

Of the patients operated under anticoagulants, 83 per cent are in Group A, having bled less than $1000 \mathrm{ml}$. The remaining 17 per cent bled more than $1000 \mathrm{ml}$.; 13 per cent of those were in Group B (1000 to $2000 \mathrm{ml}$. ) and 4 per cent in Group C (over $2000 \mathrm{ml}$.).

The majority, 88 per cent, of the untreated patients, were also in Group A with losses under $1000 \mathrm{ml}$. However, 12 per cent had blood losses over $1000 \mathrm{ml}$.

Patients having complications related to excessive bleeding have been analysed separately and the incidence in the treated and the untreated groups has been compared. Of the 96 patients operated under anticoagulants, 4 had a hæmothorax, which was treated by aspiration in 2 and by re-exploration in the other 2. All patients recovered. Three patients in the untreated group had hæmothorax-one was treated by aspiration, another by re-exploration, and one patient died. Thus the amount of blood loss and the incidence of complications due to bleeding was not increased by the use of anticoagulants.

More bleeding might be expected at a second operation upon the mitral valve, particularly if done under anticoagulants. Of the 9 patients having a second valvotomy under anticoagulants, 7 had no more blood loss than they did at their first operation, but 2 bled more. However, of 21 patients who had a second valvotomy without anticoagulants, 16 bled less than $1000 \mathrm{ml}$., as in their 
first operation, while 5 bled more (Table VI). There was thus no significant difference in bleeding between the two groups after a second operation.

\section{CONCLUSIONS}

Analysis of the present series shows that when anticoagulants are maintained with prothrombin times of 20-30 seconds for at least two weeks before mitral valvotomy both systemic and pulmonary embolism can be prevented, for no such complication occurred in 41 patients treated in this way. This contrasts with an embolic incidence of $7 \cdot 2$ per cent in inadequately treated patients and 9.5 per cent in untreated patients. The practice of discontinuing anticoagulants shortly before operation resulted in a higher incidence of emboli $(28 \%)$ than when anticoagulants were not used.

The prevention of systemic emboli in the treated series is probably due to the absence of soft clot in the left atrium at the time of operation, which has been a striking feature. Changes in operative technique which partially coincided with the introduction of anticoagulant treatment may, however, have played a part.

The study shows that anticoagulants can be safely administered before and during the operation and are not associated with increased incidence of bleeding. Furthermore, a second valvotomy is not associated with additional bleeding hazards.

\section{SUMMARY}

A series of 375 patients subjected to mitral valvotomy between 1951 and 1962 is reported; of these, 114 had been given anticoagulants before operation to prevent embolism.

Comparison of the different methods of anticoagulation used and the results obtained showed that prophylactic anticoagulants were entirely successful in preventing embolism when the therapy had been started more than two weeks before operation, maintained uninterruptedly, and the levels of prothrombin time kept over the 20 -second range at all times. By contrast, there was a $27 \cdot 7$ per cent incidence of embolism among 18 patients to whom anticoagulants had been given but then withdrawn between two weeks to 48 hours before operation.

Anticoagulation was considered inadequate in 55 patients who received anticoagulants for less than two weeks or had prothrombin times below 20 seconds. Four of them $(7 \cdot 2 \%)$ suffered embolism but of a lesser severity than the 25 patients of $261(9.5 \%)$ not anticoagulated but who also suffered embolism.

The incidence of excessive bleeding in patients undergoing first or second valvotomies was little greater in those patients given anticoagulants than it was in those not given anticoagulants.

Pre-operative anticoagulant treatment is a safe and effective method of preventing systemic or pulmonary embolism and peripheral venous thrombosis in patients undergoing mitral valvotomy.

Our thanks are due to Professor J. F. Goodwin for his helpful advice in the analysis of these results and the preparation of this paper.

\section{REFERENCES}

Beaumont, J. L., Moeri, E., and Lenègre, J. (1957). Résultats du traitement anticoagulant chez les mitraux d'après 1400 observations. Arch. Mal. Cour, 50, 225.

Carter, S. A., McDevitt, E., Gatje, B. W., and Wright, I. S. (1958). Analysis of factors affecting the recurrence of thromboembolism off' and on anticoagulant therapy. Amer. J. Med., 25, 43.

Dahlgren, S., and Björk, V. O. (1962). Thromboembolic complications in connection with mitral commissurotomy after discontinuation of anticoagulant therapy. J. thorac. cardiovasc. Surg., 43, 780.

Dubost, Ch., Blondeau, Ph., and Piwnica, A. (1962). Instrumental dilation using the transatrial approach in the treatment of mitral stenosis. A survey of 1000 cases. J. thorac. cardiovasc. Surg., 44, 392.

Glenn, F., and Holswade, G. R. (1960). Emboli in the surgical treatment of mitral stenosis. Surg. Gynec. Obstet.,

111, 289.
Goodwin, J. F. (1960). Treatment of peripheral vascular disease. I-Medical. In Pathogenesis and Treatment of Occlusive Arterial Disease; Proceedings of a Conference at Royal College of Physicians, 1959, ed. L. McDonald, p. 216. Pitman Medical Publishing Co., London. 
McDevitt, E., Carter, S. A., Gatje, B. W., Foley, W. T., and Wright, I. S. (1958). Use of anticoagulants in treatment of thromboembolism. J. Amer. med. Ass., 166, 592.

Miscall, L., Nolan, R. B., Gordon, A., and Miller, H. I. (1962). Anticoagulant agents in the surgical treatment of mitral stenosis. J. thorac. cardiovasc. Surg., 43, 382.

Ricordeau, G., and Balansa, J. (1957). Thrombose auriculaire et traitement préopératoire de la sténose mitrale. Presse méd., 65, 1730.

Storm, O., and Hansen, A. T. (1955). Mitral commissurotomy performed during anticoagulant prophylaxis with dicumarol. Circulation, 12, 981 .

Uglov, F. G., and Potashov, L. V. (1962). The prophylaxis of thromboembolic complications in surgery for mitral stenosis. J. thorac. cardiovasc. Surg., 44, 408. 